\title{
1 Structural and functional complexity of vocalizations in a cooperatively breeding passerine, Jungle
}

\section{Babbler}

3 Soniya Devi Yambem, Sonam Chorol and Manjari Jain*

4 Department of Biological Sciences, Indian Institute of Science Education and Research, Mohali, India

$7 \quad *$ Corresponding Author

9 Address correspondence to:

10 Manjari Jain

11 Department of Biological Sciences,

12 Indian Institute of Science Education and Research, Mohali,

13 Punjab 140306, India

14 manjari@iisermohali.ac.in

16 Abstract: Animal vocal communication ranges from simple to complex based on repertoire size, structure, and composition of calls and the information encoded in them. According to the social complexity hypothesis,

18 communication complexity tends to increase with an increase in social complexity. While several studies on

19 mammalian systems exist supporting this, evidence from avian systems is comparatively limited. Towards this,

20 we present evidence for complex acoustic communication in a cooperatively breeding passerine, Jungle Babbler,

21 based on three aspects of complexity: an extensive repertoire of acoustically-distinct calls, within-call structural

22 complexity and the diverse behavioural contexts in which these calls are used. Jungle Babblers were found to

23 possess a structurally and functionally diverse vocal repertoire comprising 15 different calls. Detailed acoustic

24 analyses of multisyllabic calls revealed that these calls are composed of different notes. Further, despite a large

25 number of notes present in the repertoire, the number of calls were limited to 15 . This implies that there may be

26 underlying rules that determine call composition to give rise to functional calls to which receivers respond. We

27 also found that these calls were produced in a variety of affiliative and agonistic contexts and were employed

28 towards coordination of diverse social behaviours including group movement, foraging, brood care, aggression

29 and vigilance. Yet, 7 out of 15 vocalizations were produced in the context of vigilance. This disproportionate

30 investment of vocalizations towards co-ordinated acoustic vigilance is characteristic of many cooperatively 
31 breeding birds. Our study extends support for the social complexity hypothesis and also lays the foundation for

32 future investigations on combinatorial and syntactical rules underlying call structure and function in bird 33 vocalizations.

\section{Significance statement}

36 Studies on vocal complexity in birds have focussed mainly on repertoire size, structure and function. However,

37 fine temporal and spectral features of elements that constitute a call/song are rarely examined to evaluate vocal

38 complexity. We examined complex communication in a cooperatively breeding social passerine, Jungle Babbler

39 for which we assessed repertoire size, function, acoustic features of calls and of their constituent elements.

40 Jungle Babblers were found to possess a structurally and functionally diverse vocal repertoire comprising of 15

41 calls, $46 \%$ of which were in the context of vigilance, thereby extending support to the social complexity

42 hypothesis. We also found that several calls were composed of multiple, acoustically distinct notes. These

43 findings will be foundational in understanding the interrelations between sociality and communicative

44 complexity and underlying combinatorial rules that determine call structure and function.

46 Keywords: Vocal repertoire, affiliative call, agonistic call, multisyllabic call, communicative complexity, 47 sociality.

\section{Introduction}

50 Theories on the evolution of language have long acknowledged the importance of sociality in the evolution of 51 complex communication. The social complexity hypothesis posits that communication complexity tends to 52 increase with an increase in social complexity (Blumstein and Armitage 1997). This is because social animals 53 are likely to require higher sophistication in communication to coordinate different behaviours and sustain the 54 relationships between individuals within a social group. The complexity of communication is determined by 55 both structural and functional complexity. Structural complexity of vocalizations is determined by the 56 compositional features of calls (how many elements make a call and how these elements are organized within a 57 call), overall acoustic features of the call (temporal and spectral characteristics) and the total number of unique 58 vocalizations of a species (Hailman and Ficken 1986; Zimmermann and Lerch 1993; reviewed in Freeberg et al. 59 2012). Additionally, the different behavioural contexts in which calls differ also add to the communication 60 complexity (reviewed in Freeberg et al. 2012; Crane et al. 2016). Based on the number of elements in a call, 
61 avian vocalizations can be classified as monosyllabic or multisyllabic (Rothstein 1988). A 'syllable' or 'note' is

62 the simplest element of a call and forms the smallest acoustic unit, which when combines with other such units

63 (of the same or different type) forms a 'phrase' (multisyllabic call). The total vocalization produced by an

64 animal throughout its lifetime is called a vocal repertoire (Searcy 1992). Repertoire size vary from species to

65 species, for instance, male Common Grackles have only one song type (Searcy 1992) whereas Common

66 Nightingale sings up to 180 different song types (Weiss et al. 2014). A smaller repertoire is considered as less

67 complex compared to a larger repertoire size (Blumstein and Armitage 1997).

68 The function of the call repertoire is different in different species and requires extensive behavioural 69 observations to ascertain. In many species of songbirds, complex vocalizations serve as a sexual display to 70 attract mates or as territorial display against conspecific and heterospecific individuals. It has been shown that 71 individuals with larger repertoire sizes are more successful in attaining mates (Catchpole 1987; Robinson and 72 Creanza 2019) or can hold a territory for a longer duration (Hiebert et al. 1989). It has also been reported that in 73 several species the size of the repertoire increases with complexity in vocalization context. For instance, Diana 74 monkeys produce predator-specific alarm calls (Zuberbühler 2002) whereas, in Meerkats, alarm calls vary 75 depending not only on predator type but also on the level of urgency (Manser 2001).

76 Social animals exhibit higher frequency and diversity of interactions between different individuals than solitary 77 animals and possess a larger and more complex repertoire to deliver meaningful inference (Freeberg et al. 2012;

78 Krams et al. 2012; Leighton 2017). Based on the interaction type, calls are broadly classified as either 79 'affiliative' or 'agonistic'. Calls that are used in maintaining social bonds are 'affiliative' whereas 'agonistic 80 calls are produced against conspecific and heterospecific rivals (Kondo and Watanabe 2009). Quantifying and 81 categorizing the entire repertoire based on signal structure and function can provide valuable insights into the 82 behaviour of the species and selective forces that drive the evolution of complex communication.

83 Jungle Babblers (Turdoides striata) are cooperatively breeding passerines that live in groups of 3-20 individuals 84 and are widely distributed throughout lowland India, both in rural and urban habitats (Andrews and Naik 1970;

85 Gaston 1977; Ali and Ripley 1978). Group members engage in many social behaviours such as cooperative 86 brood care, sentinel duty, collective foraging, anti-predator behaviour, allogrooming and intergroup 87 confrontations. (Andrews and Naik 1970; Gaston 1977). To maintain bonding within the social group, it is 88 expected that there would be vocalizations associated with interactive behaviours, thereby raising the possibility 89 that Jungle Babblers possess a complex communication system. Andrew and Naik (1970) and later Gaston 90 (1977) provided onomatopoeic descriptions of some vocalizations of the species and the situation in which the 
91 calls were observed, thereby raising the possibility of complex acoustic communication in this cooperative

92 breeder. However, so far, no study has examined complex acoustic communication in Jungle Babblers, despite

93 their broad distribution, the potential for multiple vocalizations and known social system. In this study, we aim

94 to examine complex acoustic communication in Jungle Babblers by a quantitative and systematic investigation

95 of the vocal repertoire of the species. The major objectives were 1. To quantify the acoustic structure of calls to

96 estimate the number of structurally distinct call types, 2. To determine the acoustic features of the constituent

97 elements (notes / syllables) of each of these call types 3. To ascertain the behavioural context associated with

98 each call type through extensive behavioural observations. This study provides the first acoustic characterization

99 of the vocalization of Jungle Babblers, carried out both across and within call type, and the associated

100 behavioural contexts. Apart from providing the bedrock for future investigations of vocal complexity in this

101 species, this study will allow a comparative investigation of complex communication in avian systems with

102 varying degrees of sociality and ecological conditions.

103

\section{Materials and methods}

105 Since the data collected for this study was completely based on observations and recordings of animals in the 106 field, it was not possible to record data blind.

\section{Study site}

108 The study was conducted in Mohali region, located in the eastern part of Punjab in northern India (30 $36^{\prime}$ and

$10930^{\circ} 45^{\prime} \mathrm{N}$ latitude and $76^{\circ} 38^{\prime}$ and $76^{\circ} 46^{\prime} \mathrm{E}$ longitude), which covers an area of about $116.50 \mathrm{~km}^{2}$. According to

110 the Koppen-Geiger climate classification system, the climate of Mohali comes under the 'Cwa' category (Kottek

111 et al. 2006). Mohali has a humid subtropical climate that is variable throughout the year with a hot summer and

112 cold, dry winter separated by a brief period of tropical monsoon climate. The habitat of the study site comprised

113 of shaded gardens and closed-canopy woodland with trees such as Populous deltiodes, Ficus religiosa, F.

114 glomerata, Vachellia nilotica, Morus alba, M. nigra, and Psidium guajava, Leucaena leucocephala, Chukrasia

115 tabularis, Callistemon sp., and shrubby habitats dominated by bushes of Lantana camara, Ricinus

116 communis and Cannabis sp. (Fig. S1).

\section{Behavioural data collection}

118 The fieldwork for this study was conducted between May 2016 and March 2020, during which we carried out 119 systematic behavioural observations to interpret the context of vocalizations of Jungle Babblers. All behavioural 120 observations were made on free-ranging birds using 8 x 42 binoculars (Nikon, Monarch 7) following Ad 
121 libitum and focal animal sampling (Altman 1974). Towards this, the vocalizing individual was identified and its

122 behaviour was noted. This was accompanied by noting the behaviour of all group members in sight and a quick

123 scan of the environment. Any response given to the signaller was also noted.

\section{Acoustic data collection}

125 Recordings were taken from free-ranging Jungle Babblers in their natural habitat at a distance of up to 10 meters

126 from the caller. A solid-state recorder (Marantz PMD661MKII; frequency response: $20 \mathrm{~Hz}-20 \mathrm{kHz}$ ), connected

127 to a super-cardioid shotgun microphone (Sennheiser ME66 with K6 PM; frequency response: $40 \mathrm{~Hz}$ to $20 \mathrm{kHz}$ ),

128 covered with a foam windscreen (Sennheiser MZW66) was used to record all vocalizations (sampling rate of

$12944.1 \mathrm{KHz}$ and 16-bit accuracy). Calls of nestling were recorded while they were inside the nest and from

130 fledgling outside the nest. Fledglings were identified based on iris colour (juvenile - black; adult - pale white;

131 Fig. S2). Recordings were also made from individuals trapped in mist-net and during their subsequent release.

132 To minimize the overlap of calls between individuals, recordings were focused on a single individual except for 133 chorus calls. While recording the vocalizations, the behaviour of the caller and receivers were noted as

134 described above and the surroundings were scanned. These observations were announced at the end of the call

135 recording. Data from the behavioural observations were then used to interpret the context of vocalizations and

136 the recordings were categorized under these behavioural categories. Andrew and Naik (1970) and Gaston (1977)

137 catalogued a list of situations in which Jungle Babblers vocalize. This list served as a valuable reference library

138 for validating our independent inferences.

\section{Acoustic analyses}

140 A total of 303 recordings comprising of 1895 calls were processed in Raven Pro 1.5 (Cornell Laboratory of 141 Ornithology, USA) and spectrograms were generated using Hann window function, size 512 with a $50 \%$

142 overlap. After generating the spectrograms, only those calls with no or minimum overlap were retained for 143 further analysis except in the case of chorus calls. For the acoustic categorization of calls, as a first step, calls 144 were classified under the same or different call type based on aural and visual inspection of the spectrograms.

145 Calls were also examined based on the inter-note interval. If the time gap between two notes was $<=0.1 \mathrm{~s}$, they 146 were considered to belong to the same call (Catchpole and Slater 2010). This allowed us to categorize all call 147 types under one of two categories: 'monosyllabic' (single note call) or 'multisyllabic'. The third category of 148 calls called 'chorus calls' included those vocalizations in which multiple individuals vocalized simultaneously.

149 Within each of these three categories detailed acoustic characterization of different calls was then carried out 150 based on 7 different acoustic features: A) spectral parameters i) frequency $5 \%(\mathrm{~Hz})$ ii) frequency $95 \%(\mathrm{~Hz})$ iii) 
151 bandwidth $90 \%(\mathrm{~Hz})$ and iv) peak frequency $(\mathrm{Hz})$; B) temporal parameters: i) call duration (s) and ii) inter-

152 note/syllable interval (s) iii) total number of notes in a call. Finally, all multisyllabic calls were subjected to

153 further analyses wherein a total number of notes in each call was identified and acoustic analyses of each

154 constituent note were carried out based on all spectral parameters and note duration. For the analyses of the

155 chorus calls, only spectral parameters were considered as signal overlap from different callers made analyses of 156 temporal features unreliable.

\section{Statistical analysis}

158 Calls that were preliminarily categorized under different call types based on behavioural observation and audio 159 and visual observation of the spectrogram. They were then subjected to rigorous statistical analyses based on

160 their acoustic features, as determined by the signal analyses carried out. For this, pairwise comparisons were 161 carried out between calls belonging to the same category (monosyllabic, multisyllabic or chorus calls). Calls 162 were considered to be different from each other if they differed significantly in at least 1 out of the 7 acoustic 163 parameters examined. Further, within call complexity was examined for all multisyllabic calls by examining 164 whether a given call was composed of multiple, acoustically distinct notes or was composed of repeats of the 165 same elements. All the statistical analysis was carried out in Statistica 64 (Dell Inc.2015, Version 12). To check 166 for normality of data, the Shapiro-Wilk's test was used. ANOVA, and Kruskal-Wallis ANOVA were performed 167 for data that followed and did not follow a normal distribution, respectively. Further, for pairwise comparisons, 168 unpaired t-test for normally distributed data and Mann-Whitney U (MW U) test for data that did not follow 169 normal distribution were carried out. This allowed us to examine if the behavioural categorization of calls as 170 different call types was consistent with the acoustic characterization and to examine the complexity of vocal 171 repertoire both across and within call types.

\section{Results}

\section{Vocal repertoire and structural complexity of calls}

175 The audio-visual inspection of the spectrogram and analyses of inter-note interval resulted in Jungle Babbler 176 vocalizations being classified into 15 different call types. Adult vocalizations included 5 monosyllabic, 6 177 multisyllabic and 2 chorus calls, whereas juvenile vocalizations included 2 call types, both of which were 178 monosyllabic (Fig. 1, Table 1). All monosyllabic adult calls were found to be significantly different from each 179 other based on their acoustic features (Kruskal-Wallis ANOVA; Table S1a). The pairwise comparison revealed 180 that all calls were significantly different from each other by at least three acoustic parameters (MW U test; Table 
181 S1b, Fig. 2a-e). The two Juvenile calls were significantly different from each other only in temporal characteristics and not based on any spectral parameters (t-test and MW U test; Table S2, Fig. 2f).

183 Similarly, there was a significant difference between all multisyllabic calls based on their acoustic features 184 (Analysis of variance; Table S3a and Kruskal-Wallis ANOVA; Table S3b; Fig. 3). The pairwise comparison 185 showed that all multisyllabic calls are also significantly different from each other (t-test and MW U test; Table 186 S3c and d Fig.3) by more than one parameter.

187 The two chorus calls were found to be not significantly different based on their spectral features (t-test and MW 188 U test, Table S4a and b).

189 Based on aural and visual inspection, we found that each multisyllabic call was composed of different note 190 types, which were then compared statistically within a call type. Multisyllabic calls were found to be composed 191 of at least three acoustically distinct note type each (Analysis of Variance, Kruskal-Wallis ANOVA and MW U 192 test; Table S5a-c; Fig. 4 and 5).

\section{Behavioural context of vocalizations}

194 This large and structurally complex vocal repertoire of Jungle Babblers was also found to be functionally diverse. The results from the behavioural observations suggest that these vocalizations are produced in 2 major

196 functional contexts: affiliative and agonistic. Detailed below are the behavioural contexts in which the signallers were observed to produce these diverse vocalizations.

\section{Affiliative calls}

199 i) Contact (Chack) call: This call is used to contact conspecifics and is produced when an individual is 200 separated from the group. In response to this call, a member of the group gives the same call back and 201 eventually approached the left behind signaller leading to a reunion of a diverted individual with the rest of the 202 group. This is a loud call that consists of only one note (monosyllabic) with faintly visible harmonics (Fig. 1a).

203 ii) Foraging (Cuk) call: This is a very soft call produced by one or more individuals of the group while 204 foraging on the ground/leaf litter. No unique behaviour or reaction was observed when this call is produced and 205 the group continues to forage. This monosyllabic call is the call with the shortest duration (Fig. 1b).

206 iii) Prompt (Ca-ca-ca) call: This call is given by an adult heading towards nest for food provisioning.

207 Nestlings respond to this call with a 'begging call' (described later). The call is multisyllabic, mainly composed 208 of 3 - 4 notes that are similar spectrally, however, note duration decreases progressively (Fig. 1c).

209 iv) Prompt flight (Long cu-cu-cu) call: This vocalization is also made when adults are in proximity to 210 fledglings, typically around nests. While producing these calls, adults take short flights from one position to 
211 another and back to the fledgling. This seems to prompt fledgling movement. Fledglings were observed to move

212 out of the nest or move from their current location to another in response to this call by adults. This

213 multisyllabic call is usually produced by more than one individual at a time and is composed of the most number

214 of notes ( $3-11$ notes per call). The notes at the beginning of the call are of longer duration and higher peak

215 frequency and forthcoming notes show a gradual decrease in both these parameters (Fig. 1d).

216 v) Flight ( $\mathrm{Cu}-\mathrm{cu}-\mathrm{cu})$ call: This call is generally produced during group displacement. The call is initiated

217 by one individual and is eventually joined in by the rest of the group members. Group movement initiates soon

218 after. This is a soft multisyllabic call composed of $3-4$ notes. Here too, notes in the beginning, have a longer

219 duration and higher frequency $95 \%$ while trailing notes progressively become shorter in duration and have lower 220 values for frequency $95 \%$ (Fig. 1e).

221 vi) Fledgling close (Chack) call: This vocalization is produced by fledglings or juveniles in close 222 proximity to adults. Adults do not respond to this call. Spectrally, this monosyllabic call is almost similar to 223 adult contact call however, adult contact calls are shorter in duration than these calls (Fig. 1f).

224 vii) Begging call: Nestlings and fledglings produce this monosyllabic call during food provisioning and in 225 response to prompt calls. Spectrally, this call is very dynamic. This call is generally accompanied with the wide 226 opening of beak and rigorous flapping of wings (Fig. 1g).

\section{Agonistic calls}

228 viii) Sentinel soft (Low chack) call: This monosyllabic call is exclusively produced by a sentinel- an 229 individual on vigilance duty, on an elevated perch, forgoing foraging while the rest of the group members 230 forage, Andrews and Naik (1970). While producing this vocalization, the caller is generally not very alert and 231 may even groom at times. There is no visible change in the behaviour of group members in response to this call 232 (Fig. 1h).

233 ix) Threat (Shriek) call: This call is produced in response to the sudden approach of a potential threat. Both

234 the caller and receiver usually respond instantly with a startle and take shelter in the closest tree or foliage. After 235 a while, inside the cover, they might start grooming or allogrooming or resume regular behaviour (generally 236 foraging). This call is monosyllabic but sometimes two notes may be produced in continuation. Among all 237 monosyllabic calls, this call has the highest peak frequency (Fig. 1i).

238 x) Distress (Kya-kya-kya) call: This is a loud monosyllabic call produced repeatedly by an individual in 239 distress. Such a situation may arise when an individual gets trapped in mist-net or is handled by a human or a 
240 predator. This call attracts group members towards the caller. Among all monosyllabic call, this call has the 241 highest note duration (Fig. 1j).

242 xi) Alert (Cackle) call: During intrusion by any potential threat, a perched individual produces this call, 243 accompanied by periodic hops from one side to the other, flapping of wings and twitching of tail up and down.

244 This call may induce other members of the group to join in the vocalization, whereas on other occasions no 245 visible response from the group members is observed. This call is a multisyllabic call comprising of $2-4$ 246 different notes. As the call proceeds, there is a decrease in note duration and minimum frequency (frequency $2475 \%$ ) whereas the frequency bandwidth (bandwidth 90\%) increases progressively (Fig. 1k).

248 xii) Harsh (Khack) call: This is a noisy harsh call, produced by any perched individual in response to any 249 intrusion which is not an immediate threat, including the observer. This call is also produced while individuals 250 are foraging in the foliage or are in the queue for food provisioning. There was also no visible response by group 251 members in response to this call. This call is multisyllabic and comprises of 1-5 notes forming a phrase (Fig. 11).

252 xiii) Intermediate alert (Khack cackle) call: Any perched individual produces this call in the presence of the 253 observer but also for other intruders. The intensity of the caller's behaviour is somewhat intermediate to the 254 harsh and alert call. No visible response was observed from the group. The call comprises of 6 structurally 255 different notes/syllables with highest call duration (Figure $3 \mathrm{j}$ and 3k). Moreover, there is no fixed pattern in the 256 composition of the call (Fig. 1m).

257 xiv) Mobbing (Wheezy cackle) call: This vocalization is a chorus call wherein more than one individual at a 258 time is involved. It was observed to be produced in the presence of an immediate and proximate predator such 259 as domestic/feral cats, Indian Grey Mongoose, Greater Coucal, Spotted Owlet, Barn Owl, snakes, and Bonnet 260 Macaque. While making this call, all individuals involved, flutter around and 'harass' the potential predator 261 until the predator retreats. However, if the predator did not move from its position, then the group disperses 262 from the location. This vocalization also attracts neighboring heterospecific birds to join in mobbing the 263 predator accompanied by loud and urgent vocalizations. It may, however, be noted that while producing 264 mobbing calls, Jungle Babblers were not observed making any physical interactions with the predator (Fig. 1n).

$265 \mathrm{xv}$ ) Intergroup fight (guttural noise) call: This is also a chorus call, produced when two different groups of 266 Jungle Babblers come in contact with each other. They produce this vocalization while moving from one tree to 267 another, chasing each other. Along with this vocalization, sometimes individuals engage in mid-air physical 268 fights, striking each other using beaks and claws while falling to the ground, after which they usually disengage. 269 Concurrently other members of the groups surround the fighting pair while producing this vocalization. They 
270 also make this call by positioning themselves facing each other on different trees without physical interaction. It

271 may be noted, however, that intergroup fights are rare (Fig. 1o).

\section{Discussion}

274 The major drivers of vocal complexity in avian systems include sexual selection and sociality (MacDougall-

275 Shackleton 1997; Freeberg et al. 2012) and measures of complexity include both structural (repertoire size and

276 features of calls) and functional (behavioural contexts) aspects of vocalizations (Crane et al. 2016; Holt 2017).

277 Cooperative breeding has been found to be a strong predictor of large repertoire size in avian systems (Leighton

278 2017) and several avian cooperative breeders possess multiple structurally-distinct calls (Ficken et al. 1978;

279 Seddon 2002; Warrington et al. 2014; Crane et al. 2016). Evaluation of overall structural complexity, however,

280 must also incorporate an assessment of the fine structure of all vocalizations by measuring the temporal and

281 spectral features of elements (notes/syllables) that constitute a call/song. This level of analysis is largely missing

282 in the assessment of vocal complexity in social birds (Greig et al. 2008; Grieves et al. 2015; Crane et al. 2016).

283 In this study, we examined communicative complexity in Jungle Babblers by examining repertoire size, overall

284 acoustic features of all calls, and their constituent elements, and the behavioural contexts in which vocalizations

285 are produced. The vocal repertoire of Jungle Babblers comprises of 7 monosyllabic and 8 multisyllabic calls. All

286 calls were structurally distinct from each other. Note-level analyses within multisyllabic calls revealed that each

287 call were constructed by the combination of several acoustically distinct notes (call type (number of distinct

288 notes): prompt (3), flight (3), prompt flight (4), alert (4), harsh (4), intermediate alert (6)). While 31 notes were

289 recorded in the vocal repertoire of this species, the functional repertoire size is limited to 15 calls. This implies

290 that this large variety of notes combine in a limited number of ways to form meaningful calls. It is also possible

291 that some of the notes are shared across different calls and examining this would require across call note

292 comparisons. This study thereby lays the foundations to further investigations on understanding the limits of

293 combinatorial rules that determine the composition of meaningful multisyllabic calls in this social bird.

294 With respect to the functional aspects of the vocal repertoire, our findings are consistent with the observations of

295 Andrews and Naik (1970) and Gaston (1977) that various affiliative and agonistic behaviours are mediated by

296 vocalizations in Jungle Babblers. Affiliative calls include those that coordinate group movement as well as food

297 provisioning and brood care. For instance, flight call in Jungle Babblers clearly induces all group members to

298 cohesively displace to a new location and contact call functions to reunite lost or left-behind members with the

299 rest of the group. Calls like prompt and prompt flight induce fledglings to beg and fly, respectively. Similar 
300 findings have been reported in Pied Babblers that produces 'purrs' that prompt fledglings towards a food source

301 and 'clucks' to induce group displacement (Engesser et al. 2017). The exact function of the foraging call in

302 Jungle Babblers remains unclear. We speculate that similar to foraging calls in Pied Babblers, this call may play

303 a role in maintaining the spacing between the foragers in order to enhance foraging efficiency (Radford and

304 Ridley 2008).

305 Our findings also suggest that 8 out of 15 vocalizations of Jungle Babblers are produced in agonistic context

306 towards conspecifics and heterospecifics. It includes inter-group fight calls (guttural noise) produced against

307 conspecific rivals and 6 others, including threat, distress, harsh, intermediate alert, alert, and mobbing calls that

308 are produced against heterospecifics, mainly potential predators. This disproportionately high representation of

309 calls towards vigilance could be because predation imposes a strong selective pressure by directly impacting the

310 fitness of an individual (Leighton 2017). It is known that vigilance behaviour is costly since the animals must

311 interrupt foraging in order to scan the environment for predators (Wickler 1985). By having coordinated

312 acoustic vigilance, individuals can mitigate this cost as it renders visual scans by every individual unnecessary.

313 This, however, is contingent on the animals producing reliable alarm calls, allowing receivers to choose the

314 appropriate escape strategy, thereby increasing the chance of survival (Marler 1967). Thus, it would be useful to

315 have functionally referential alarm vocalizations that inform the receivers about the category of predator (aerial

316 or terrestrial or even predator specific; Seyfarth et al. 1980; Naguib et al. 1999). It would also be useful to

317 encode the level of urgency (encoding distance of potential threat) to allow the receivers to respond in an

318 appropriate time (Manser 2001). All of these together is likely to increase the proportional representation of

319 vigilance vocalization in the vocal repertoire of cooperative breeders. Meerkats, for instance, are known to

320 possess 30 different vocalizations of which $18(60 \%)$ are produced in the context of vigilance. Similar to our

321 findings, studies on other cooperatively breeding birds have shown that a large number of vocalizations are

322 dedicated to vigilance. This includes Chestnut-crowned Babblers (4 out of 13 calls; Crane et al. 2016), Pale-

323 winged Trumpeter (5 out of 12 calls; Seddon et al. 2002) and Black-capped Chickadees (5 out of 11 calls;

324 Ficken et al.1978). In a study carried out on 253 bird species across the globe, representing 59 families, it was

325 found that cooperative breeders dedicated a significantly higher proportion of their vocal repertoire to vigilance

326 related vocalizations (Leighton 2017).

327 Alarm calls can be categorised into three main types: flee, mob and distress (reviewed in Magrath et al. 2015).

328 Flee-type calls are generally short duration pure tone calls making them difficult to localize (Marler 1955). In

329 Arabian Babblers, alarm calls produced by foragers were found to be much shorter as compared to those 
330 produced by sentinel, since foragers were only able to witness the threat in proximity whereas sentinel perceived

331 it from a distance (Sommer 2011). Our results also suggest that the alarm vocalizations produced by foragers,

332 threat call, is monosyllabic with the shortest note duration and functions as a flee call. However, alarm calls like

333 harsh, intermediate alert and alert produced by sentinel or individuals on perch were found to be multisyllabic

334 calls. We speculate that different alarm calls of Jungle Babbler - harsh, intermediate alert and alert are produced

335 in relation to low, intermediate and high urgency of the threat, however, this needs further examination. We

336 speculate that the sentinel soft call could serve the function similar to the 'watchman song' reported in other

337 cooperative breeders (Wickler 1985, Manser 1999, Hollén et al. 2008). The 'watchman song' is a form of

338 acoustic coordination between vigilant (sentinel) and non-vigilant (foragers) group members, which serves as a

339 proxy for the presence of sentinel on duty for the rest of the group (Wickler 1985). It can be considered as both

340 affiliative and agonistic as it helps in maintaining group cohesion as well as provides information about the

341 predation risk (Kern and Radford 2013).

342 Overall, our study on the social behaviour and acoustic communication of a sexually monomorphic,

343 cooperatively breeding passerine, Jungle Babbler, extends support to the social complexity hypothesis. The

344 broad distribution of this species in India and its disproportionate investment in vigilance calls make it a good

345 model system to study vigilance behaviour in groups occupying diverse habitats with disparate predation

346 pressures. The quantitative categorization of different call types to note level in our study has rarely been carried

347 out. This along with the information on variation in the acoustic features of notes provides a rich database for

348 future research on understanding rules governing multisyllabic call composition and information encoding in

349 avian vocalizations. While the overall behavioural contexts of the vocalizations are evident from our findings,

350 understanding the proximate function of some of the vocalizations such as the foraging, sentinel soft and

351 intermediate alert will require further studies, including manipulative experiments using field playbacks. This

352 study will be foundational to all such future investigations.

\section{Acknowledgements}

355 We gratefully acknowledge the help received from Nakul Raj, Ranjit, Gurtej and Sandeep towards conducting

356 the fieldwork and members of BEL, IISER-M for useful discussions. We thank the Director, NIPER for 357 necessary permits to conduct fieldwork at NIPER campus. MJ is grateful to SKM for introducing her to 358 ornithology and to JB for taking over parental care for our fledgling when needed.

\section{Funding information}


360 The research was funded by a grant from Science and Engineering and Research Board, Department of Science

361 and Technology (YSS/2015/001606) to MJ and received infrastructural support from IISER Mohali. SDY and

362 SC were supported by Senior Research Fellowships from University Grant Commission, Government of India.

\section{Author contributions}

364 MJ conceived and designed the study. SDY carried out all the field work and acoustic analyses for repertoire

365 size, call characteristics and for behavioural data. SC carried out all the field work and acoustic analyses for note

366 level complexity. SDY, SC and MJ carried out all statistical analyses and wrote the manuscript. All authors

367 approved the final version of the manuscript.

368 Data availability

369 The datasets generated are available as supplementary material

370 Compliance with ethical standards

371 Conflict of interest

372 The authors declare that they have no conflict of interest.

\section{Ethical approval}

374 Jungle Babblers are listed in Schedule IV under the Indian Wildlife Protection Act (1972) and designated as 375 'Least Concern' by IUCN's Red List of Threatened Species. This study was conducted with necessary permits 376 (No. 3625) from Department of Forest and Wildlife Preservation, Government of Punjab, India, and with the 377 approval of Institute Animal Ethical Committee (IISER/SAFE/PRT/2018/003), IISER Mohali, India. No 378 animals were harmed or kept in captivity for this study.

379

\section{$380 \quad$ References}

381

382 1. Ali S, Ripley SD (1978). Handbook of the birds of India and Pakistan, 2nd edn, vol. 1

383 2. Altmann J (1974). Observational study of behavior: sampling methods. Behaviour 227-267

384 3. Andrews MI, Naik NM (1970). The biology of the Jungle Babbler. Pavo 8:1-34

385 4. Blumstein DT, Armitage KB (1997). Does sociality drive the evolution of communicative complexity? A

386 comparative test with ground-dwelling sciurid alarm calls. Am Nat 150:179-200

387 5. Catchpole CK (1987). Bird song, sexual selection and female choice. Trends Ecol Evol 2:94-97.

388 6. Catchpole CK, Slater PJ (2010). Bird song: biological themes and variations. Cambridge University Press. 
7. Crane JM, Savage JL, Russell AF (2016). Diversity and function of vocalisations in the cooperatively breeding Chestnut-crowned Babbler. Emu 116:241-253.

8. Engesser S, Ridley AR, Townsend SW (2017). Element repetition rates encode functionally distinct information in Pied Babbler 'clucks' and 'purrs'. Anim Cogn 20:953-960.

9. Ficken MS, Ficken RW, Witkin SR (1978). Vocal repertoire of the Black-capped Chickadee. The Auk. 95:34-48.

10. Freeberg, TM, Dunbar RI, Ord TJ (2012). Social complexity as a proximate and ultimate factor in communicative complexity. Phil. Trans. R. Soc. B 367:1785-1801

11. Gaston AJ (1977). Social behaviour within groups of Jungle Babblers (Turdoides striatus). Anim Behav 25:828-848.

12. Greig E, Pruett-Jones S (2008) Splendid songs: the vocal behaviour of Splendid Fairy-wrens (Malurus splendens melanotus). Emu 108:103-14.

13. Grieves LA, Logue DM, Quinn JS (2015) Vocal repertoire of cooperatively breeding Smooth $\square$ billed Anis.

14. Hailman, JP, Ficken, MS (1986). Combinatorial animal communication with computable syntax: Chick-a-

$$
\text { dee calling qualifies as" language" by structural linguistics. Anim Behav 34:1899-1901 }
$$

15. Hiebert SM, Stoddard PK, Arcese P (1989). Repertoire size, territory acquisition and reproductive success in the Song Sparrow. Anim Behav 37:266-273.

16. Hollén LI, Bell MB, Radford AN (2008). Cooperative sentinel calling? Foragers gain increased biomass intake. Curr Biol 18:576-579.

17. Holt J, Barati A, McDonald PG (2017) The complex acoustic repertoire of a highly social species, the Noisy Miner, Manorina melanocephala. Emu 117:19-30.

18. Kern JM, Radford AN (2013). Call of duty? Variation in use of the watchman's song by sentinel Dwarf

413 19. Kondo N, Watanabe S (2009). Contact calls: information and social function. Jpn Psychol Res 51:197-208.

414 20. Kottek M, Grieser J, Beck C, Rudolf B, Rubel F (2006). World map of the Köppen-Geiger climate 415 classification updated. Meteorol Z 15:259-263.

416 21. Krams I, Krama T, Freeberg TM, Kullberg C, Lucas JR (2012). Linking social complexity and vocal 417 complexity: a parid perspective. Phil. Trans. R. Soc. B 367:1879-1891. 
418 22. Leighton GM (2017). Cooperative breeding influences the number and type of vocalizations in avian 419 lineages. Proc R Soc Lond B 284:20171508.

420 23. MacDougall-Shackleton SA (1997). Sexual selection and the evolution of song repertoires. Curr Ornithol $421 \quad 14: 81-124$.

422 24. Magrath RD, Haff TM, Fallow PM, Radford AN (2015). Eavesdropping on heterospecific alarm calls: from mechanisms to consequences. Biol Rev 90:560-586.

25. Manser MB (2001). The acoustic structure of Suricates' alarm calls varies with predator type and the level of response urgency. Proc R Soc Lond B 268:2315-2324.

26. Manser, M. B. (1999). Response of foraging group members to sentinel calls in Suricates, Suricata suricatta. Proc R Soc Lond B 266:1013-1019.

27. Marler P (1955). Characteristics of some animal calls. Nature. 176:6-8.

429 28. Marler P (1967). Animal Communication Signals: We are beginning to understand how the structure of 430 animal signals relates to the function they serve. Science, 157:769-774.

431 29. Naguib M, Mundry R, Ostreiher R, Hultsch H, Schrader L, Todt D. (1999) Cooperatively breeding Arabian Babblers call differently when mobbing in different predator-induced situations. Behav Ecol. 10:636-40.

30. Radford AN, Ridley AR (2008). Close calling regulates spacing between foraging competitors in the groupliving Pied Babbler. Anim Behav 75:519-527.

31. Robinson CM, Creanza N (2019). Species $\square$ level repertoire size predicts a correlation between individual song elaboration and reproductive success. Ecol Evol 9:8362-8377.

32. Rothstein SI, Yokel DA, Fleischer RC (1988). The agonistic and sexual functions of vocalizations of male Brown-headed Cowbirds, Molothrus ater. Anim Behav 36(1), 73-86.

439 33. Searcy WA (1992). Song repertoire and mate choice in birds. Am Zool 32:71-80.

440 34. Seddon N (2002). The structure, context and possible functions of solos, duets and choruses in the 441 Subdesert Mesite (Monias benschi). Behaviour. 139:645-76.

442 35. Seddon N, Alvarez A, Tobias J (2002). Vocal communication in the Pale-winged Trumpeter (Psophia 443 leucoptera): repertoire, context and functional reference. Behaviour. 139:1331-59.

444 36. Seyfarth RM, Cheney DL, Marler P. Monkey responses to three different alarm calls: evidence of predator classification and semantic communication. Science. 210:801-3.

446 37. Sommer C (2011). Alarm calling and sentinel behaviour in Arabian Babblers. Bioacoustics 20:357-368. 
447 38. Warrington MH, McDonald PG, Sager AK, Griffith SC (2014). The vocal repertoire of the cooperatively

$448 \quad$ breeding Apostlebird (Struthidea cinerea). Emu. 114:206-21.

449 39. Weiss M, Hultsch, H, Adam I, Scharff C, Kipper S (2014). The use of network analysis to study complex

$450 \quad$ animal communication systems: a study on Nightingale song. Proc R Soc Lond B 281:20140460.

451 40. Wickler W (1985). Coordination of vigilance in bird groups: The" watchman's song" hypothesis. Z

$452 \quad$ Tierpsychol 69:250-253

453 41. Zimmermann E, Lerch C (1993). The complex acoustic design of an advertisement calls in male Mouse

454 Lemurs (Microcebus murinus, Prosimii, Primates) and sources of its variation. Ethology 93:211-224.

455 42. Zuberbühler K (2002). A syntactic rule in forest monkey communication. Anim Behav 63:293-299. 
458 Table 1 Temporal and spectral characteristics of 15 vocalizations type of Jungle Babbler showing mean \pm std. $\mathrm{N}$ and $\mathrm{n}$ correspond to the number of recordings and calls for

460 used by Gaston (1977)

\begin{tabular}{|c|c|c|c|c|c|c|c|c|c|c|c|}
\hline \multirow[b]{2}{*}{ S. no } & \multicolumn{2}{|c|}{ Call types } & \multirow[b]{2}{*}{$\mathrm{N}$} & \multirow[b]{2}{*}{$\mathrm{n}$} & \multirow[b]{2}{*}{ No. of notes } & \multirow[b]{2}{*}{$\begin{array}{c}\text { Call duration } \\
\text { (s) }\end{array}$} & \multirow[b]{2}{*}{$\begin{array}{l}\text { Inter-note } \\
\text { interval (s) }\end{array}$} & \multirow[b]{2}{*}{$\begin{array}{l}\text { Frequency } \\
5 \%(\mathrm{kHz})\end{array}$} & \multirow[b]{2}{*}{$\begin{array}{l}\text { Frequency } \\
95 \%(\mathrm{kHz})\end{array}$} & \multirow{2}{*}{$\begin{array}{l}\text { Frequency } \\
\text { bandwidth } \\
90 \%(\mathrm{kHz})\end{array}$} & \multirow{2}{*}{$\begin{array}{c}\text { Peak } \\
\text { frequency } \\
(\mathrm{kHz})\end{array}$} \\
\hline & $\begin{array}{c}\text { Behavioural } \\
\text { context }\end{array}$ & $\begin{array}{c}\text { Onomatopoeic } \\
\text { description }\end{array}$ & & & & & & & & & \\
\hline 1 & Contact & Chack * & 33 & 175 & 1 & $0.13 \pm 0.02$ & - & $1.75 \pm 0.28$ & $3.76 \pm 0.41$ & $2.02 \pm 0.55$ & $2.68 \pm 0.22$ \\
\hline 2 & Fledgling close & Fledgling chack & 10 & 41 & 1 & $0.15 \pm 0.02$ & - & $1.58 \pm 0.26$ & $4.28 \pm 0.98$ & $2.70 \pm 1.01$ & $2.66 \pm 0.34$ \\
\hline 3 & Begging & Begging & 14 & 78 & 1 & $0.24 \pm 0.05$ & - & $1.42 \pm 0.4$ & $4.82 \pm 0.83$ & $3.40 \pm 0.98$ & $3.01 \pm 1.05$ \\
\hline 4 & Foraging & Cuk* & 17 & 63 & 1 & $0.05 \pm 0.01$ & - & $0.92 \pm 0.13$ & $5.73 \pm 0.71$ & $4.81 \pm 0.67$ & $1.67 \pm 0.60$ \\
\hline 5 & Prompt & Ca-ca-ca & 19 & 47 & $4.45 \pm 1.4$ & $0.31 \pm 0.13$ & $0.04 \pm 0.01$ & $0.91 \pm 0.19$ & $5.75 \pm 1.40$ & $4.84 \pm 1.36$ & $1.59 \pm 0.35$ \\
\hline 6 & Flight & $\mathrm{Cu}-\mathrm{cu}-\mathrm{cu} *$ & 31 & 79 & $3.68 \pm 0.65$ & $0.30 \pm 0.06$ & $0.05 \pm 0.01$ & $0.89 \pm 0.28$ & $4.26 \pm 0.67$ & $3.36 \pm 0.80$ & $1.81 \pm 0.45$ \\
\hline 7 & Prompt flight & Long cu-cu-cu & 22 & 60 & $7.07 \pm 3.88$ & $0.55 \pm 0.31$ & $0.04 \pm 0.01$ & $0.92 \pm 0.20$ & $4.60 \pm 0.97$ & $3.68 \pm 1.06$ & $1.67 \pm 0.35$ \\
\hline 8 & Threat & Shriek* & 12 & 17 & 1 & $0.1 \pm 0.02$ & - & $2.33 \pm 0.38$ & $6.00 \pm 0.88$ & $3.67 \pm 0.82$ & $4.11 \pm 1.33$ \\
\hline 9 & Sentinel soft & Low chack & 21 & 99 & 1 & $0.1 \pm 0.02$ & - & $1.02 \pm 0.16$ & $4.95 \pm 0.95$ & $3.92 \pm 0.99$ & $2.35 \pm 0.46$ \\
\hline 10 & Distress & Kya-kya-kya & 22 & 220 & 1 & $0.32 \pm 0.06$ & - & $1.88 \pm 0.20$ & $5.25 \pm 1.1$ & $3.37 \pm 1.14$ & $3.04 \pm 0.71$ \\
\hline 11 & Alert & Cackle* & 23 & 363 & $4.14 \pm 2.91$ & $0.54 \pm 0.34$ & $0.05 \pm 0.01$ & $1.58 \pm 0.33$ & $6.46 \pm 0.72$ & $4.87 \pm 0.76$ & $3.45 \pm 0.95$ \\
\hline 12 & Harsh & Khack & 38 & 332 & $1.57 \pm 0.78$ & $0.34 \pm 0.25$ & $0.07 \pm 0.02$ & $1.36 \pm 0.30$ & $5.50 \pm 1.17$ & $4.14 \pm 1.02$ & $2.73 \pm 0.85$ \\
\hline 13 & Intermediate alert & Khack cackle & 19 & 299 & $2.98 \pm 1.26$ & $0.90 \pm 0.30$ & $0.06 \pm 0.01$ & $1.67 \pm 0.21$ & $5.81 \pm 0.79$ & $4.14 \pm 0.67$ & $3.27 \pm 0.80$ \\
\hline 14 & Mobbing & Wheezy cackle * & 15 & 15 & - & - & - & $1.85 \pm 0.12$ & $6.40 \pm 0.55$ & $4.55 \pm 0.53$ & $4.12 \pm 0.58$ \\
\hline 15 & Inter-group fight & Guttural noise * & 7 & 7 & - & - & - & $1.63 \pm 0.31$ & $6.05 \pm 0.38$ & $4.42 \pm 0.40$ & $3.89 \pm 0.48$ \\
\hline
\end{tabular}


463 Fig.1 Spectrograms of different call types of Jungle Babbler. Affiliative calls: a contact; $\mathbf{b}$ foraging; $\mathbf{c}$ prompt;

$464 \mathbf{d}$ prompt flight; $\mathbf{e}$ flight; $\mathbf{f}$ fledgling close and $\mathbf{g}$ begging. Agonistic calls: $\mathbf{h}$ sentinel soft; $\mathbf{i}$ threat; $\mathbf{j}$ distress; $\mathbf{k}$

465 alert; $\mathbf{I}$ harsh; $\mathbf{m}$ intermediate alert; $\mathbf{n}$ mobbing and $\mathbf{o}$ intergroup fight

467 Fig. 2 Variation in different monosyllabic call types of adult and juvenile of Jungle Babblers based on 5 468 different acoustic parameters. Adult calls: a call duration; b frequency 5\%; c frequency 95\%; d bandwidth 90\% 469 and e peak frequency. Juvenile calls: f call duration. Roman numbers on the $\mathrm{x}$-axis correspond to different call 470 types: i contact; ii sentinel soft; iii threat; iv distress; $\mathbf{v}$ foraging; vi begging; and vii fledgling close. Different 471 alphabets represent the statistical difference between call types. Bar corresponds to mean with $95 \%$ confidence 472 interval

474 Fig. 3 Variation in different multisyllabic calls of adult based on 7 acoustic parameters. a number of notes; b inter-note interval; c call duration; $\mathbf{d}$ frequency $5 \%$; $\mathbf{e}$ frequency 95\%; $\mathbf{f}$ bandwidth $90 \%$; and $\mathbf{g}$ peak frequency. Roman numbers on the x-axis correspond to different call types; i alert; ii harsh; iii intermediate alert; iv flight; $\mathbf{v}$ prompt flight; and vi prompt. Different alphabets represent the statistical difference between call types. Bar corresponds to mean with $95 \%$ confidence interval

Fig. 4 Variation in notes within multisyllabic affiliative call. a note duration of 4 note types of prompt call; $\mathbf{b}$ note duration and $\mathbf{c}$ frequency $95 \%$ and bandwidth $90 \%$ of 3 note types of flight call; and $\mathbf{d}$ note duration and $\mathbf{e}$ peak frequency of 7 note types of prompt flight calls. Different alphabets represent the statistical difference between call types. Bar corresponds to mean with $95 \%$ confidence interval

Fig. 5 Variation in notes by temporal and spectral parameter within multisyllabic agonistic calls. a note duration and $\mathbf{b}$ frequency $5 \%$ and bandwidth $90 \%$ of 4 note types of alert call; $\mathbf{c}$ note duration and $\mathbf{d}$ frequency $95 \%$, bandwidth $90 \%$ and peak frequency of 6 notes of harsh call; and $\mathbf{e}$ note duration, $\mathbf{f}$ frequency $5 \%$ and frequency 95\% and $\mathbf{g}$ bandwidth $90 \%$ and peak frequency of 6 note types of intermediate alert call. Different alphabets represent the statistical difference between call types. Bar corresponds to mean with $95 \%$ confidence interval 


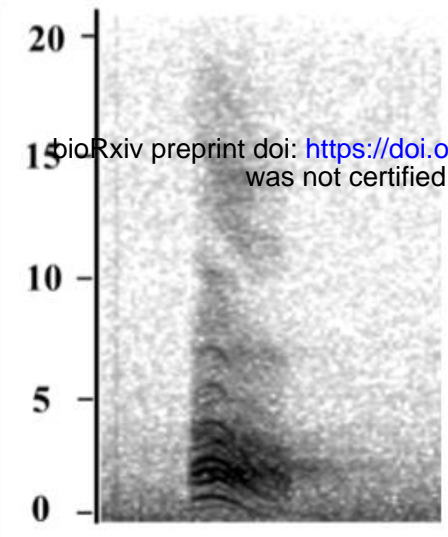

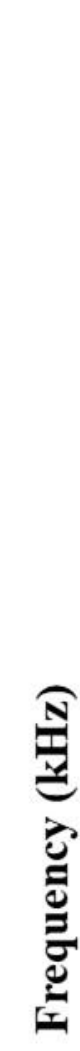

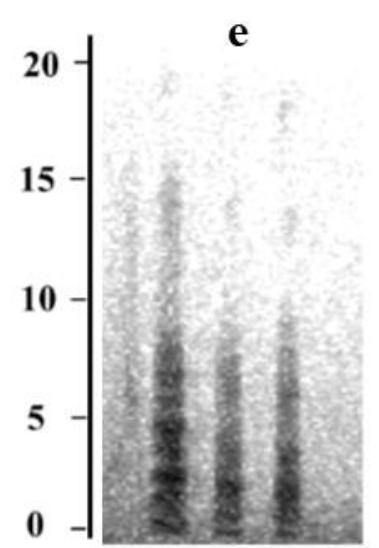

h
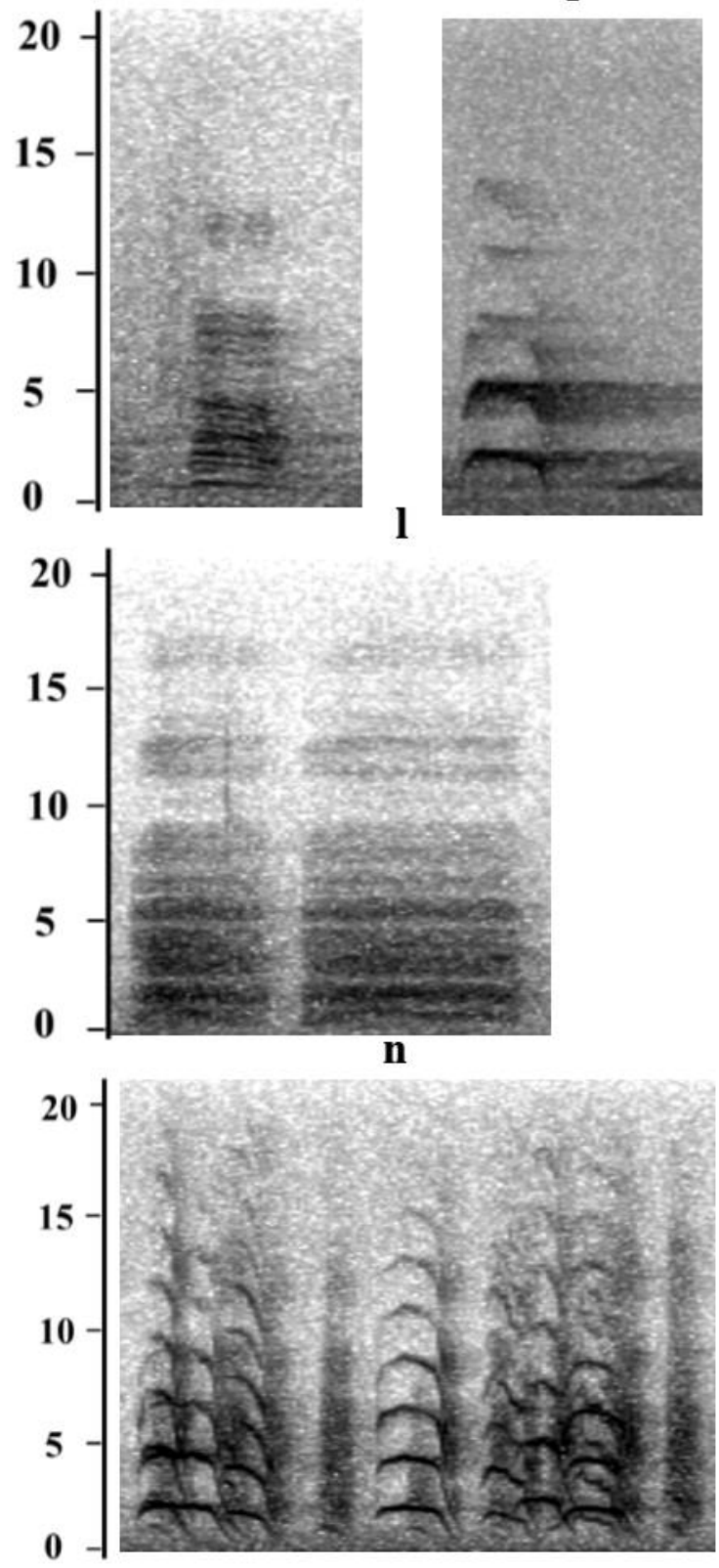

f

i

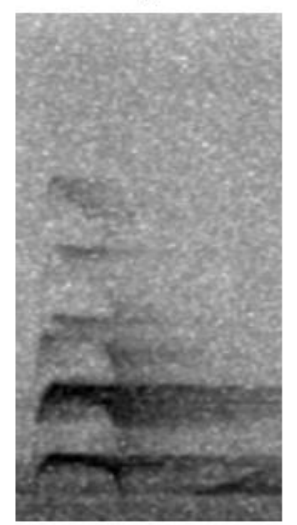

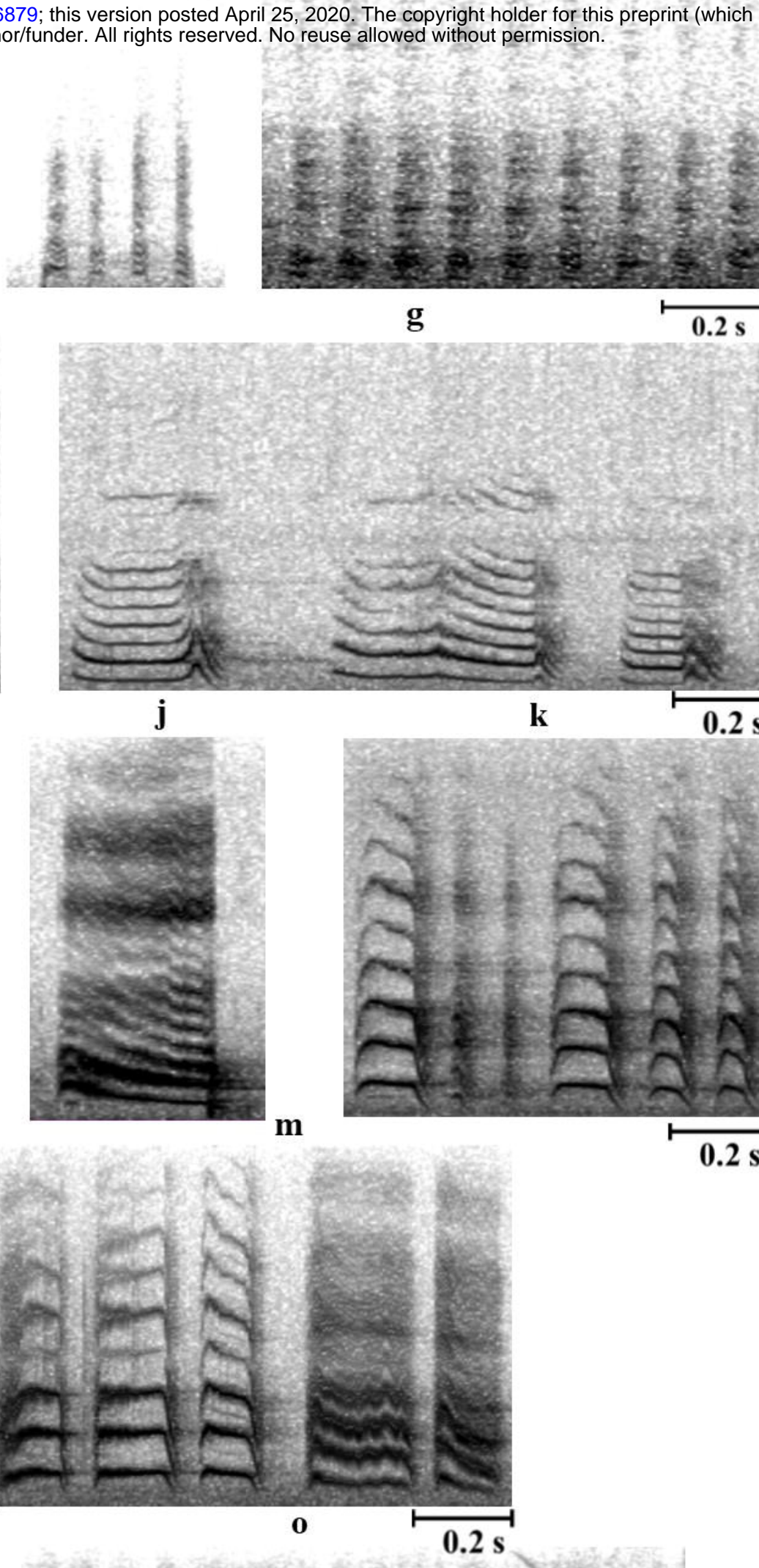
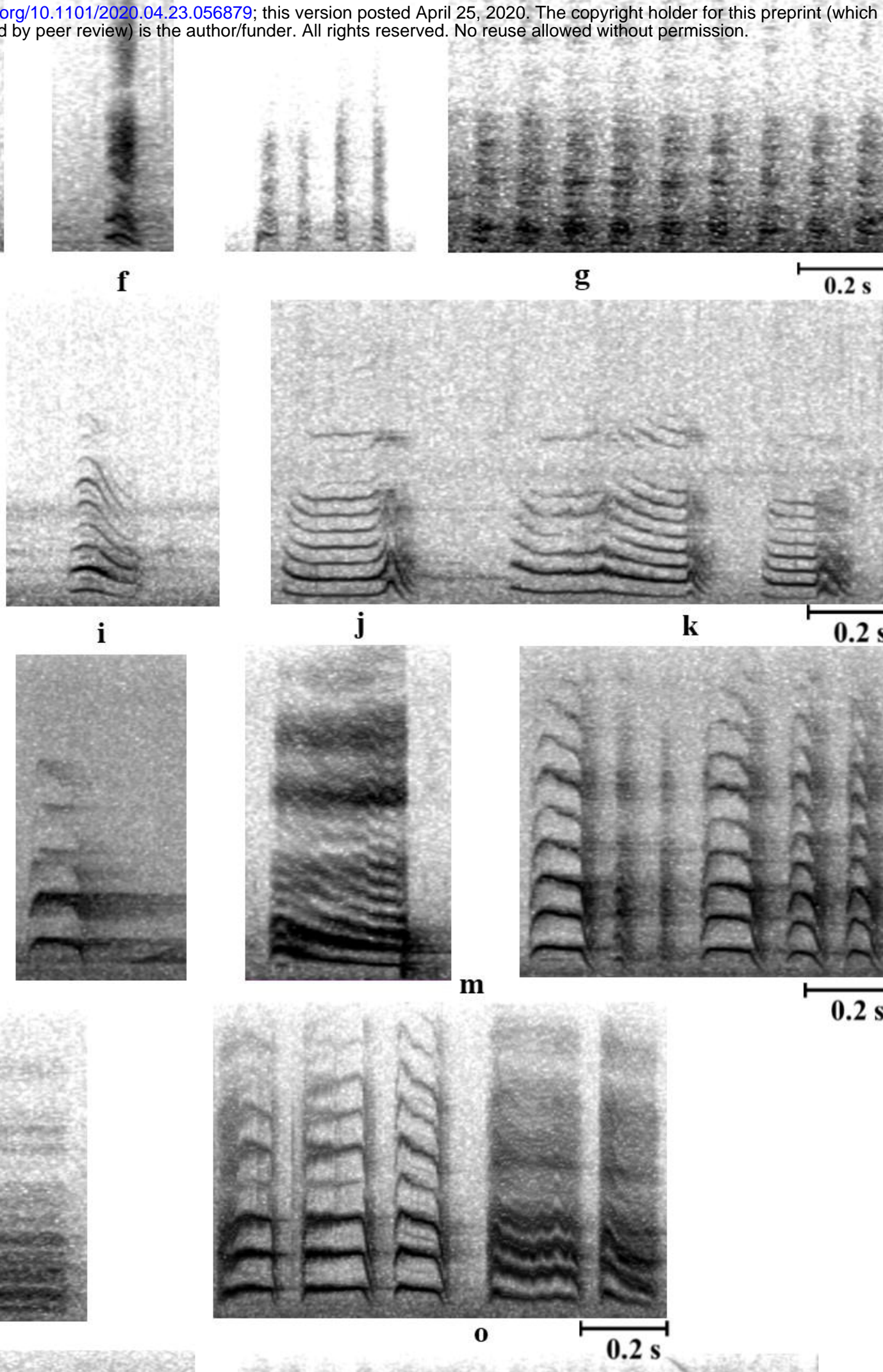

m
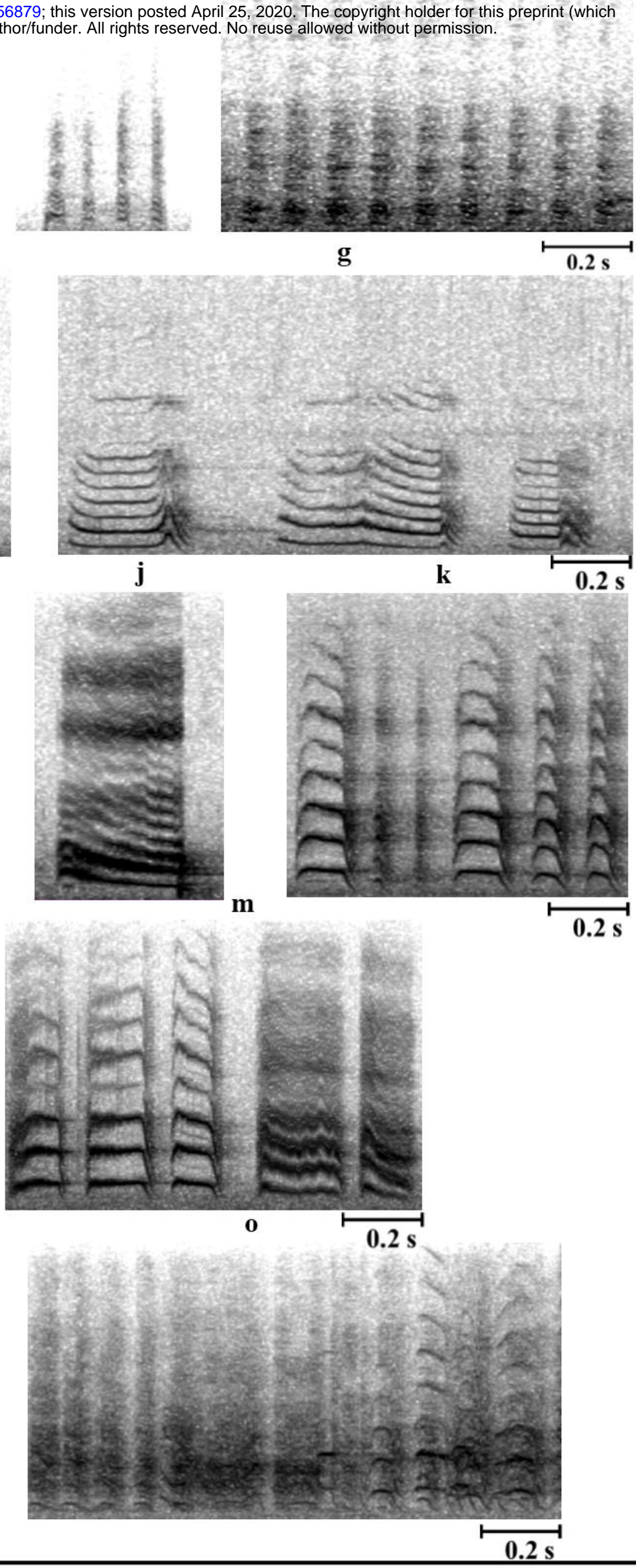

Time (s) 

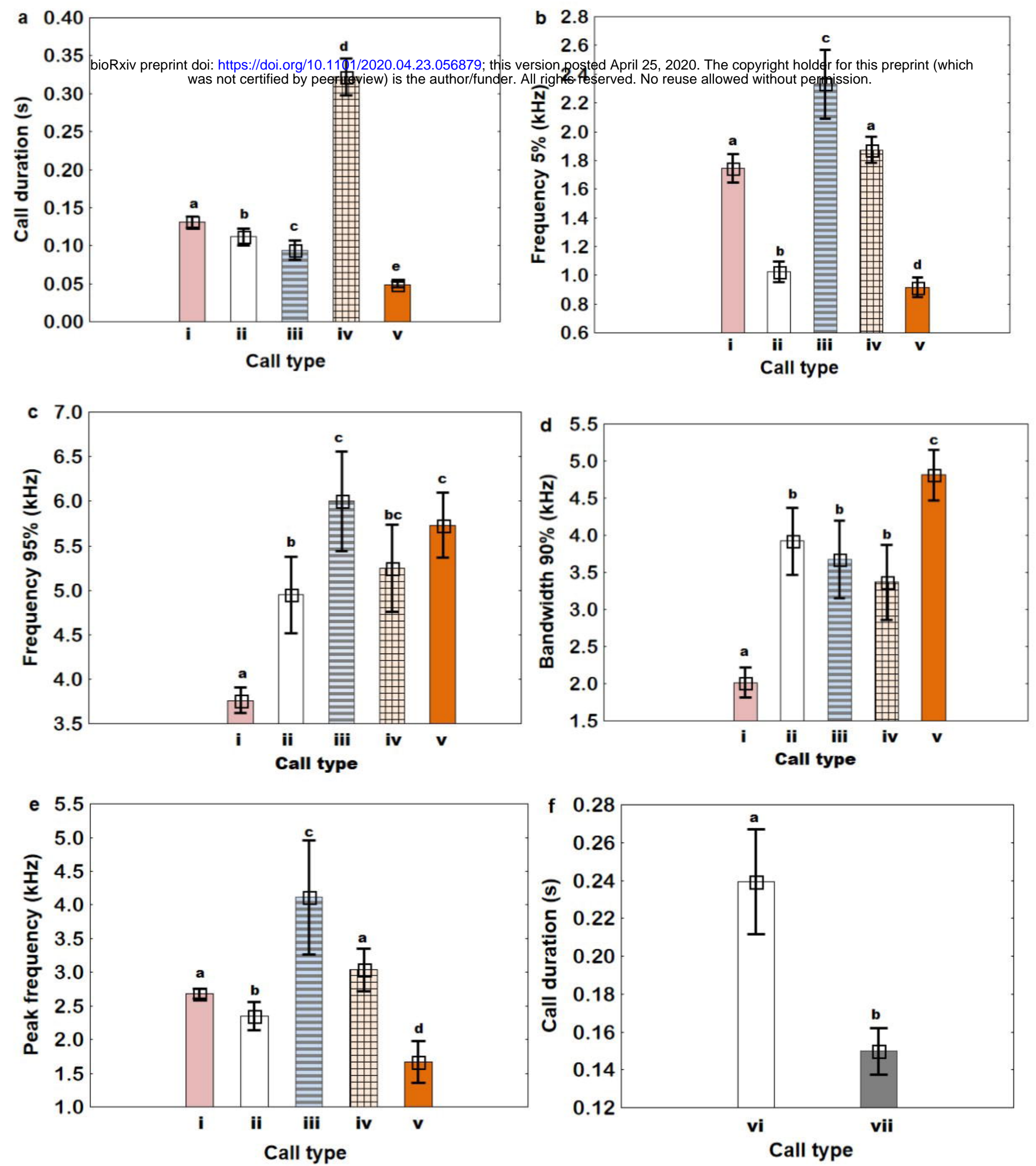
bioRxiv preprint doi: https://doi.org/10.1101/2020.04.23.056879; this version posted April 25, 2020. The copyright holder for this preprint (which was np fortifiptefpepr review) is the author/funder. All rights reserved. No reuse allowed without permission.

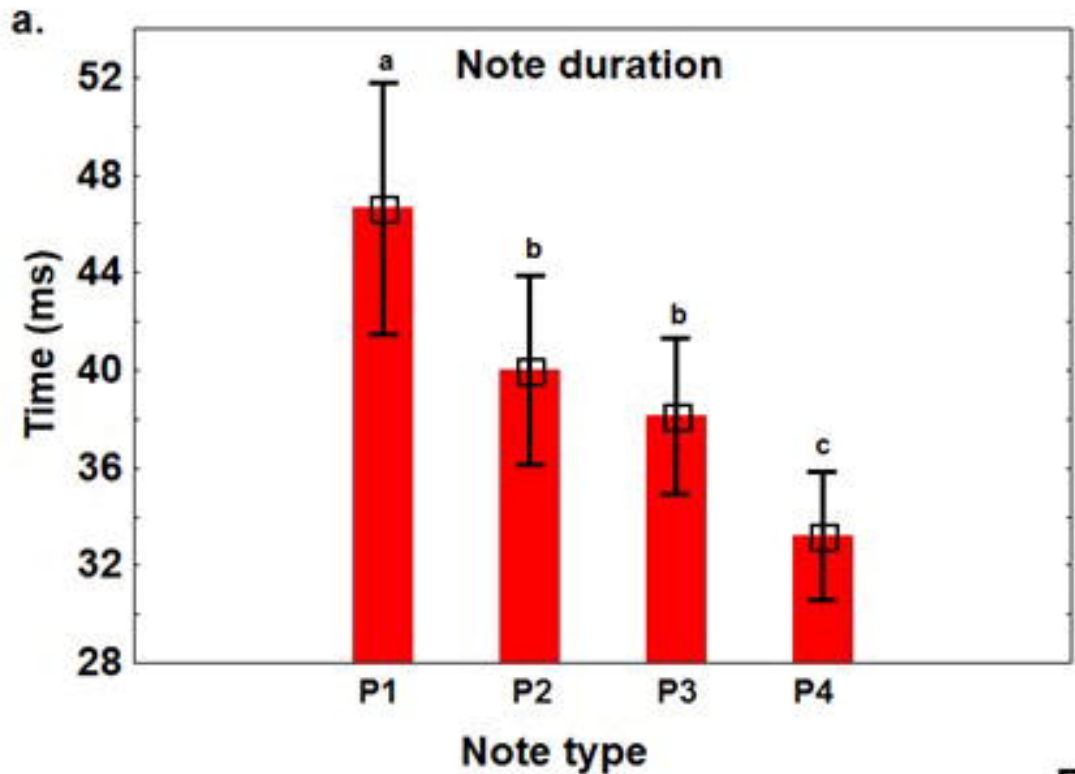

Flight call
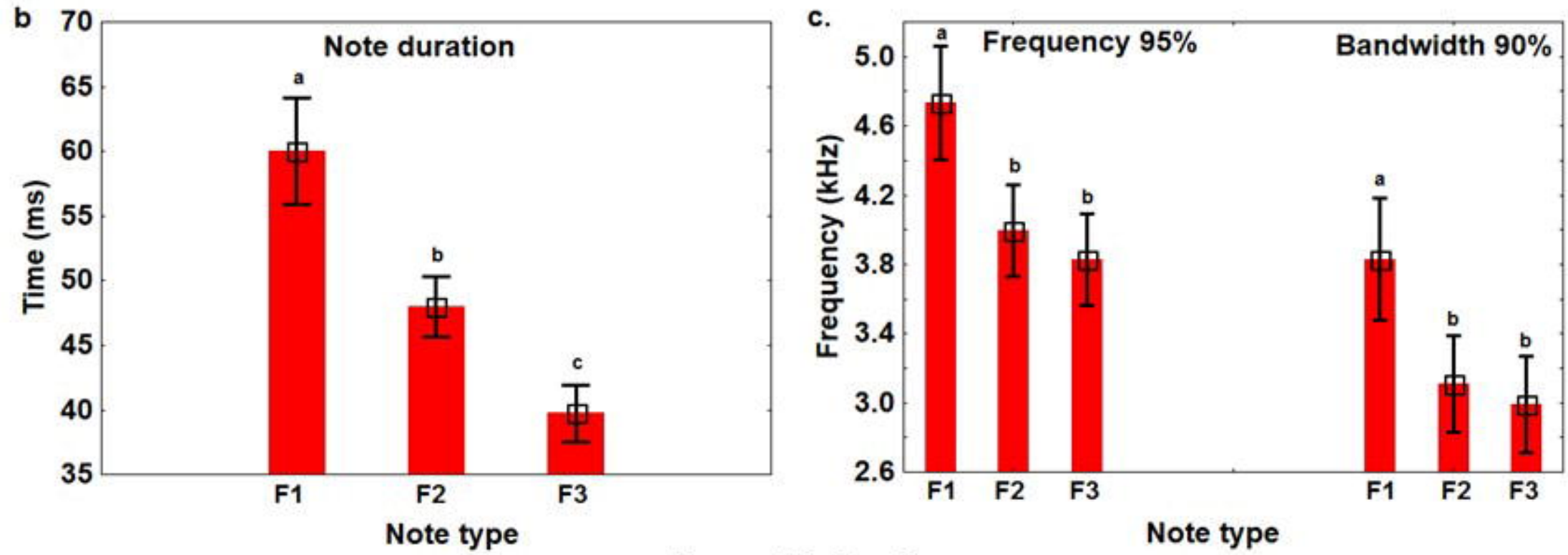

Prompt flight call
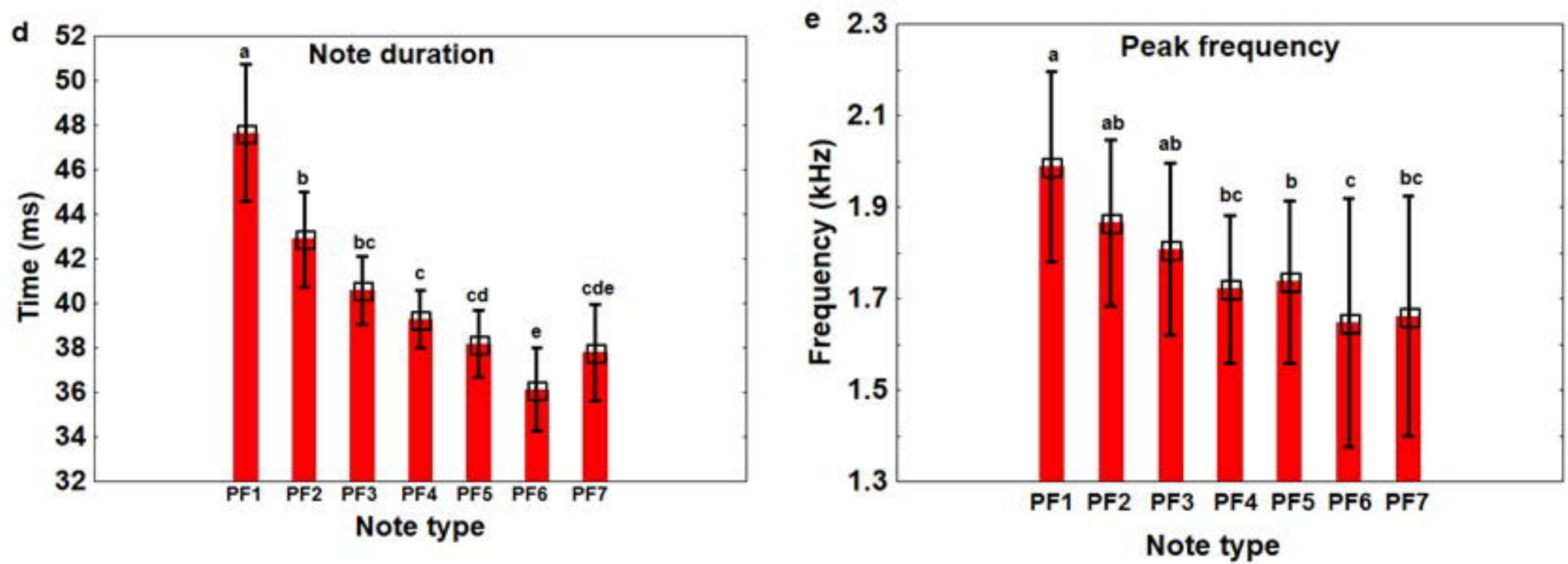


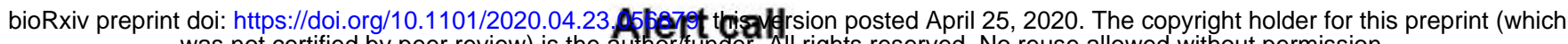
was not certified by peer review) is the authorffunder. All rights reserved. No reuse allowed without permission.
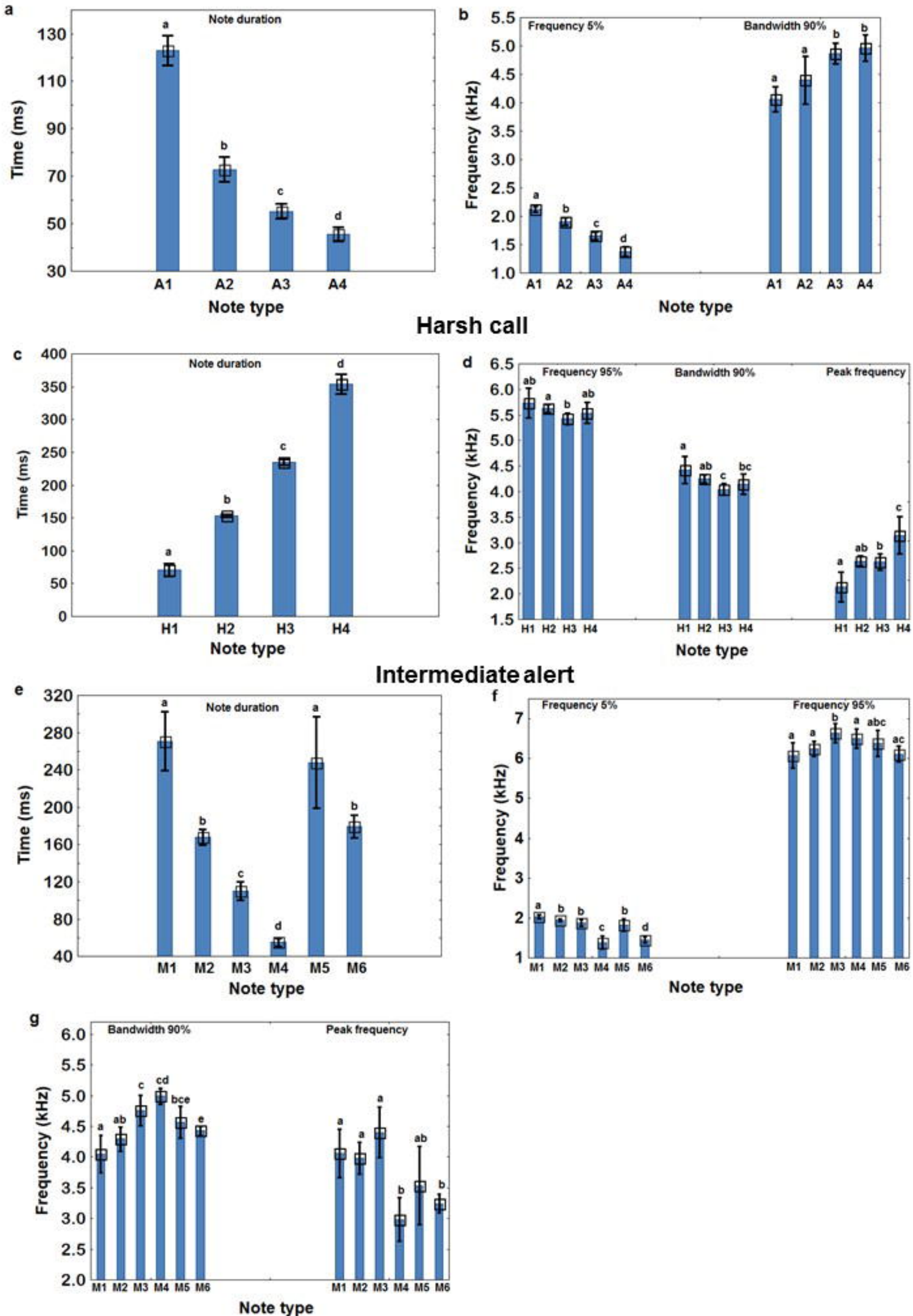